\title{
Derecho sanitario y régimen jurídico del medicamento
}

\author{
Health law and legal regime of medicine
}

\section{María Elena Balmori Gómez}

Investigadora de GRIDES (Grupo de Investigación en Derecho Sanitario y Bioética, Observatorio de la Salud Pública de Cantabria, Fundación Marqués de Valdecilla). Técnico Superior del Servicio de Asesoramiento Jurídico de la Consejería de Sanidad y Servicios Sociales (Gobierno de Cantabria). Vocal del Comité Ético de Investigación Clínica de Cantabria. Santander, España.

Bajo el título Derecho sanitario y régimen jurídico del medicamento, Viviana Denk y María Cristina Cortesi presentan una obra en la que, al hilo de la legislación vigente en Argentina, efectúan un riguroso análisis técnico de algunos aspectos fundamentales del Derecho Sanitario como son, precisamente el derecho a la salud y el derecho sanitario, la gestión de conflictos y la gestión de riesgos en salud y el régimen jurídico del medicamento. En este sentido, la propia portada de la obra comentada anticipa tanto la estructura formal de la misma como las materias que van a ser objeto de comentario y análisis por parte de las autoras, cuya exégesis se completa, además, con una breve recopilación de legislación y jurisprudencia, ofreciendo al lector, de esta manera, una visión global del tratamiento que las cuestiones abordadas merecen por parte de los órganos legislativos y judiciales argentinos.

En efecto, se trata de una obra que aparece estructurada en tres partes claramente diferenciadas desde el punto de vista formal, pero a su vez interconectadas desde el punto de vista de las materias abordadas. Así, en la parte primera y bajo la rúbrica "el derecho a la salud y el derecho sanitario", destaca el estudio pormenorizado que las autoras efectúan del régimen jurídico vigente en materia derechos y deberes del paciente, analizando fundamentalmente la regulación contenida en la Ley 26.529, modificada por la Ley 26.742, y en la Ley 153 de la Ciudad Autónoma de Buenos Aires.

Este examen de la normativa argentina vigente en materia de derechos y deberes de los pacientes aparece sin embargo, precedido de un análisis sobre las vicisitudes que ha experimentado el reconocimiento del derecho a la salud en Argentina incluyendo una breve reseña histórica, una descripción del sistema de 
salud del citado país y una referencia al concepto y alcance del denominado Derecho Sanitario, lo cual, desde el punto de vista sistemático, permite contextualizar adecuadamente las materias objeto de estudio y enmarcar con mayor acierto los análisis posteriores contenidos en la obra facilitando su comprensión.

Tras este pórtico, se aborda el estudio de los derechos del paciente en su relación con los profesionales de la salud, tomando como referencia la regulación vigente contenida en la Ley 26.529, la información sanitaria, el consentimiento informado, la historia clínica, las directivas anticipadas, los derechos del paciente reconocidos en la Ley Básica de Salud de la Ciudad de Buenos Aires (Ley 153), y los deberes del paciente.

Esta primera parte de la obra se cierra con una referencia a los derechos del equipo de salud y al denominado "Código de Ética para el Equipo de Salud" elaborado por la Sociedad de Ética en Medicina de la Asociación Médica Argentina (AMA).

La segunda parte, titulada "gestión de los conflictos y riesgos en salud", comienza analizando el problema de la judicialización del acto médico, sus posibles causas, las vías de la judicialización y sobre todo las consecuencias negativas que se derivan de someter cada vez con mayor frecuencia a la decisión de los órganos judiciales la resolución de conflictos que tienen su origen en el ámbito sanitario y que debieran ser resueltos más a menudo en este ámbito.

A continuación se hace referencia a la gestión de riesgos en salud, destacando la importancia que tiene actualmente, en el marco de una medicina cada vez más compleja, la adecuada gestión de los denominados efectos adversos, en aras de conseguir una mayor seguridad y por tanto, una mayor calidad asistencial.

Finalmente, esta parte se cierra con una referencia a la gestión de los conflictos en salud ahondando en la idea de buscar instrumentos que permitan evitar la excesiva judicialización del acto médico y, en su caso, facilitar la resolución de los posibles conflictos que puedan surgir en el propio ámbito sanitario.

La tercera y última de las partes en que está estructurado el volumen comentado está dedicada al estudio del régimen jurídico del medicamento y comienza con un apartado introductorio en el que se analiza la definición de medicamento al tiempo que se enumeran las distintas normas que definen el marco normativo vigente en Argentina en lo que a esta materia se refiere. 
No cabe duda del interés que suscita la materia objeto de análisis desde el punto de vista jurídico. Pese a su evidente funcionalidad terapéutica, curativa o rehabilitadora, los medicamentos no pueden considerarse productos totalmente inofensivos o inocuos, sino que presentan importantes riesgos para la salud y la vida de las personas, especialmente en el marco de un contexto industrializado en el que la producción de fármacos se realiza a gran escala. La crisis de la talidomida, que ocasionó miles de víctimas, es el ejemplo prototípico de materialización de estos riesgos, al tiempo que marcó, a mediados de los años sesenta del siglo XX, un punto de inflexión en la actitud de los legisladores estatales ante los fármacos destinados al mercado.

A partir de entonces, se ha asistido a una universal proliferación de normas legales cuyo objetivo fundamental es garantizar la calidad, la seguridad y la eficacia de los medicamentos. Precisamente esta cuestión, junto con la responsabilidad de los laboratorios fabricantes de los fármacos, es objeto de análisis en el apartado segundo de esta parte tercera, bajo la rúbrica "los medicamentos, calidad y seguridad".

Íntimamente relacionado con el tema de la seguridad, abordan, a continuación las autoras, los aspectos jurídico-penales de otro asunto de importancia capital y de gran actualidad, como es la seguridad del paciente frente al problema de los medicamentos ilegítimos, centrando la atención en la respuesta penal que se ha dado a este problema en Argentina a partir de la definición del concepto de "medicamento ilegítimo" que, en palabras de las propias autoras, "abarca mucho más que la adulteración y la falsificación", considerándose "como tales también los que ingresan al mercado de contrabando o robados, las muestras médicas cuya comercialización está prohibida, o los que se encuentran vencidos o adulterada la fecha de lote o vencimiento".

Tras analizar los aspectos penales antes reseñados, con expresa atención a las modificaciones legislativas más recientes que han afectado a esta materia, las autoras dedican un apartado a la ética y la responsabilidad en la prescripción y dispensación, analizando la responsabilidad que corresponde tanto al médico, que es quien efectúa la prescripción, como al farmacéutico, a cuyo cargo se encuentra la venta o comercialización de fármacos.

La venta de medicamentos fuera de los mercados formales, en particular el comercio a través de internet, es otro de los aspectos que merece una atención 
específica en esta obra en la medida en que tales mercados pueden servir como canales de entrada para la comercialización de medicamentos falsificados.

Especial interés tiene dentro de esta tercera parte de la obra, el apartado dedicado al uso off label y contraindicado de medicamentos, con especial dedicación a las cuestiones éticas y de responsabilidad profesional que este uso plantea. Así, tras analizar el marco normativo aplicable al uso de medicamentos fuera de ficha técnica, se aborda la cuestión relativa a la posible inclusión de este tipo de tratamientos dentro de las prestaciones obligatorias que se ofrecen por los distintos subsistemas de salud, para, finalmente, hacer referencia a la problemática que plantea el acceso a medicamentos de alto costo y a los denominados "acuerdos de riesgo compartido" como alternativa de financiación de los medicamentos basada en los resultados.

El último apartado, anterior a las conclusiones, hace referencia a la trazabilidad de los medicamentos, en tanto que instrumento de control de gran eficacia en la lucha contra el tráfico de medicamentos ilegítimos, en la medida en que permite controlar toda la información y documentación relevante en la vida de un medicamento.

Completa la obra comentada un anexo que contiene una parte de legislación y otra de jurisprudencia. Entre la selección de textos legislativos se incluye la Ley 26.529 comentada en la parte primera de la obra al tratar las cuestiones relativas a los derechos y deberes del paciente.

Especial interés tiene el apartado dedicado a la jurisprudencia, en el que se incorpora una selección de sentencias relacionadas con algunos aspectos tratados a lo largo de la obra, y que permiten comprobar las orientaciones adoptadas por los órganos judiciales argentinos en torno a las mismas. Así, y a modo de ejemplo, se recoge una sentencia dictada el 5 de julio de 2012 por el Juzgado de Primera Instancia en lo Criminal y Correccional de Mar del Plata en la que se declara la validez de un instrumento de directivas anticipadas (figura prevista en el artículo 11 de la Ley 26.529 de Derechos del paciente) en el que un enfermo terminal - quien presente neoplasia pulmonar con metástasis cerebrales - asienta su intención de no ser sometido a tratamientos médicos que impliquen sufrimiento e inútil prolongación de la vida.

Junto al manifiesto interés que presenta la minuciosa fundamentación jurídica que el juzgador efectúa en torno a la cuestión principal planteada, cabe destacar el tratamiento que recibe la cuestión suscitada por la Defensora Oficial al hilo de la 
misma, en torno a la necesidad de poder contar con una vía más sencilla para poder plasmar voluntades anticipadas en el caso de personas que no disponen de recursos económicos y que, por tanto, no pueden acudir a la otra vía legalmente prevista para oficializar el instrumento de directivas anticipadas, que consiste en formalizar dicho instrumento por escrito ante escribano público.

En definitiva y pese a que el análisis de las cuestiones planteadas se efectúa en el marco del régimen normativo vigente en Argentina, la universalidad de las mismas determina que la obra comentada tenga gran interés para todos aquellos implicados en su estudio, necesitados de su conocimiento por su actividad profesional, así como para los investigadores de derecho sanitario. En este sentido, para quienes desarrollen su labor profesional en este país, este libro será sin duda de gran utilidad por la vigencia de sus referencias legales y el análisis técnico jurídico que de las mismas se efectúa. Pero al mismo tiempo, su carácter fluido y la amplitud e importancia de las materias abordadas lo configuran como una herramienta de enorme interés para quienes no conociendo con tanta profundidad el funcionamiento del sistema de salud argentino, tratan de aproximarse al mismo, pues aporta una magnífica visión panorámica de este sistema y del tratamiento jurídico que merecen las cuestiones abordadas.

DENK, Viviana y CORTESI, María Cristina, Derecho Sanitario y Régimen Jurídico del Medicamento, Buenos Aires : Editorial Visión Jurídica, 2013. ISBN 978-987-29679-0-1

Visión Libros

Calle San Benito, 15

Madrid 28029 España

www.visonlibros.com/

pedidos@visonnet.es

$+34.91 .3117696 / 7139301$

Recebido para publicação em 27 de janeiro de 2014. Admitido para publicação em 12 de fevereiro de 2014. 